\title{
GLOBAL RURAL NURSING STUDENT EXCHANGE: ENGAGING WITH THE CHASE MODEL AND FOSTERING WORLDVIEW INTELLIGENCETOWARDS SOLUTION-FOCUSED COMMUNITY WELLBEING
}

\author{
Jean Ross, Diana VanderWoude, Audrey Snyder, \\ Elizabeth Merwin, Corey Hamilton Kilgore and Lisa M. Feller
}

\section{INTRODUCTION}

This paper shares a pilot project designed to provide student nurses, from diverse countries, with the opportunity to gain a global rural healthcare perspective while creating solution-focused community health interventions. Nurses play a critical role in reducing disparities in rural healthcare around the globe (Ross, 2016). The main objective of this pilot project is to raise student nurse awareness of community development in the rural healthcare context and the significant opportunity for nursing to impact health outcomes. The pilot is a unique partnership, initially developed between an international and a local New Zealand provider, a community foundation, the International Rural Nurse Organisation and participating schools of nursing.

Guided by the Community Health Assessment Sustainable Education (CHASE) model (Ross, Crawley \& Mahoney, 2017), the student nurse learners participating in this pilot will be working collaboratively with local students to identify the health needs of an aligned rural community over a three-week period. The CHASE model will be adapted to accommodate both the learners and international needs. Also, students will be exposed to the Worldview Intelligence Model (Nagel \& Jourdain, 2019) to equip them to lead inclusive conversations and build strength from cultural and geographical differences. The pilot will use videography and photo image as a medium to document the students' learning journey (Garner, 20I4; Leipert \& Anderson, 20I2) and share that journey with a larger audience, while also co-creating a model for international academic practice and community foundation partnerships.

\section{BACKGROUND}

The rural population accounts for almost half of the total global population, and people in rural areas often suffer more than their suburban and metropolitan counterparts due to lack of access to healthcare, which is in turn related to the lack of providers including specialists, travel issues and/or cost (Jones, Parker, Ahearn, Mishra, \& Veriyam, 2009). Those living in rural areas are more likely to develop and succumb to heart disease, cancer, chronic lower respiratory disease and stroke, or die from unintentional injury (Moy, Garcia, Bastian, Rossen, Ingram, \& Faul, 20 17). The infant mortality rate is higher among rural children and life expectancies for men and women in isolated regions are less than those in urban areas (Ely et al., 2017). 
According to analysts at the Kaiser Family Foundation in the United States, isolated rural populations often develop collective customs and habits that directly affect their health (Orgera \& Artiga, 20 I 8). For instance, Alaskan Natives, American Indians, African Americans and Hispanic individuals living in rural regions are more likely to avoid seeking routine and emergency medical care than white residents, due to both historical obstacles to healthcare access and other variables such as language. Others living in rural communities indulge in long-standing negative personal habits that adversely affect their health. According to research from the US Department of Health and Human Services $(H H S)$, rural adults are more likely to abuse alcohol and drugs, smoke cigarettes and lead sedentary lifestyles (Gamm, Hutchison, Dabney, \& Dorsey, 20 I0). These practices may lead to the development of chronic health conditions.

Health disparities are also found in the New Zealand population and are associated with socioeconomic deprivation and poor health outcomes including the incidence of mortality, hospitalisations, health risk factors, chronic disease and many acute conditions (Hogarth \& Rapata-Hanning, 20I5). Life expectancy is similar for both rural and urban populations in New Zealand. However, there is a difference in life expectancy between Māori and non-Māori populations (Hogarth \& Rapata-Hanning, 2015). Rural Māori (the indigenous population of New Zealand) have a shorter life expectancy than urban Mãori, with 1.2 years difference for women and 1.5 years difference for men (National Health Committee, 2010). Mori experience a higher rate of cancer, a higher incidence of obesity and higher rates of chronic illnesses stemming from obesity (Hogarth \& Rapata-Hanning, 20 I5). Chronic illnesses such as diabetes mellitus, coronary heart disease, stroke and high blood pressure are also more common among Māori (Hogarth \& Rapata-Hanning, 2015).

According to Rural WONCA (an active network of rural family doctors and rural academics from each of the world's regions), despite the huge differences between developing and developed countries, access is the major issue in rural health around the world (Couper, Strasser, Rourke, \&Wynn-Jones, 2015). Even in countries where the majority of the population lives in rural areas, resources are concentrated in the cities. All countries have difficulties with transport and communication, and all face the challenge of shortages of doctors and other health professionals in rural and remote areas.

Nurses make up the largest segment of the global healthcare profession (WHO, 20I3) and are in a position to play a critical role in reducing rural health disparities (Ross, 2016). Rural nurses need broad-based knowledge, a cradle-to-grave perspective on health and to be committed to learning to work and collaborate in new models of healthcare (Ross, 2016). They must also be capable of working with the rural community to gather and analyse population-level data; promote wellness and disease prevention; assist in adopting and disseminating best practices for population health; and identify patients who are at greater risk of disparities, necessitating greater outreach efforts (Ross \& Crawley, 20 18).

\section{THE PILOT PROJECT}

The pilot project is designed to provide student nurses (the learners), from diverse countries, with the opportunity to gain a global rural healthcare perspective while creating solution-focused community health interventions. These interventions are in alignment with the United Nations Sustainable Development Goals (United Nations, 2019). In order to provide learners with the skills and confidence to undertake community development as it relates to health, learners will engage with the CHASE model that provides nurses with a method to undertake a valid research process while gathering data related to health outcomes. For nurse educators, the CHASE model gives student nurse learners the opportunity to impact positively on health outcomes and reduce disparities.

The brief of this pilot project is to work initially in partnership with two rural communities (regional and international) to generate data with which to inform and adapt the original CHASE model, which was designed by Ross et al. (2017) from the School of Nursing at Otago Polytechnic, Dunedin, New Zealand. The CHASE model is recognised internationally as a valid tool that can be adapted to individual countries' needs in order to reduce rural health 
disparities and as a teaching and learning tool in the area of community development for undergraduate nurse learners. It is therefore envisaged that this model will be adapted to meet the needs of global learners and the identified community/s, and will enhance the viability, utilisation and implementation of healthcare delivery in rural regions across the globe. The adapted CHASE model will also augment the collaborative relationships of student nurse learners in the global landscape and will inform nursing curricula and teaching and learning internationally.

In addition, to complement the CHASE model, students will be exposed to the Worldview Intelligence Model (Nagel \& Jourdain, 2019) to equip them to lead inclusive conversations and build strength from differences. Worldview Intelligence concepts offer an approach to exploring assumptions, beliefs and value systems in reflective and curious rather than adversarial or defensive ways, providing the potential for more comprehensive approaches and solutions. In addition, the pilot will begin with a cultural and contextual orientation phase and will close with a reflective debrief process.

\section{PROJECT OBJECTIVES}

A primary objective of the rural nursing student exchange programme will be to evaluate whether the CHASE model can be adapted for use in rural communities throughout the world. While in America, students from New Zealand will utilise the CHASE model to guide community assessment and intervention in the mountainous region of rural Appalachia, home to high numbers of poverty-stricken and medically underserved individuals and families. This region will provide rich opportunities to develop impactful community-based interventions. With a grounding in the CHASE model, students will gain experience working collaboratively with local practitioners and members of the interprofessional team as they care for this rural population.

Similarly, students from America will work alongside faculty and students in New Zealand to implement the CHASE model while designing community-based interventions. Learners in the rural nursing student exchange program will earn academic credit for population-health nursing requirements. As part of their experience, students will engage in debriefing and reflection about the unique aspects of rural nursing practice and the need to develop proficient nurse generalist skills in order to meet the complex needs of rural populations. Students will be exposed to the Worldview Intelligence Model so that they are equipped to lead inclusive conversations and build strength from differences.

In addition to encouraging intellectual exploration the Worldview Intelligence concept offers the potential for more comprehensive approaches and solutions to emerge on a spectrum of issues ranging from mildly oppositional to completely divisive to seemingly unsolvable (Nagel \& Jourdain, 2019). The five principles of Worldview Intelligence are:

I. Each of us has a unique worldview (as does each organisation, community, system and culture)

2. Worldview Intelligence is a relational approach, recognising that individual and collective experiences are locally and socially constructed

3. The ability to hold and invite multiple perspectives (or worldviews) allows us to build strength from differences, to make better decisions and to make progress on issues that matter

4. It is in the intersections between worldviews where the greatest opportunities and innovations lie

5. Worldviews shift and change, and we can be intentional about how this process is invited. 


\section{PRESENTATION OF PILOT}

For the purposes of this project, students will receive instructions on the concepts behind the photovoice method including ethical considerations and the participant's use of camera or video to minimise risk to patients/clients (Garner, 20 I4; Leipert \& Anderson, 2012). The specific goals of the photovoice project are to

- enable students to record and reflect on the rural culture experience and identify strengths and challenges in the rural environment,

- $\quad$ promote critical dialogue and knowledge about rural culture and health through large and small group discussion of photographs and videos.

\section{FUTURE COLLABORATION}

Future work will adapt the CHASE model to accommodate the specific requirements of each organisation and/ or country's individual needs and requirements. This work will ensure that the model will demonstrate strategic foresight, guide student learning and make a difference to the health of rural people, globally. These efforts will capture the changes achieved through the media, in written form, videography and photo image, and will be shared nationally and internationally. Further opportunities for publication will be available while engaging with the global contemporary worldview in alignment with the WHO and United Nations 17 Sustainable Development Goals, with collegial international multidisciplinary engagement including the International Rural Nurse Organisation and dissemination of findings.

In 2022 additional funding will be sought to establish an International Community Development Symposium hosted by Otago Polytechnic in Dunedin, New Zealand, and to bring together the international fellows aligned with this project. The aim will be to establish a Global Centre for Community Sustainable Resilience. One intention of this group will be to compile a book based on our community development work, data collection and analysis, as well as the impact of this work on community healthcare outcomes and reduction of health disparities.

Jean Ross (미 0000-0003-2467-9233) RN, BN, MA Nursing, PhD, FCNA (NZ) is associate professor in nursing at Otago Polytechnic, Dunedin, New Zealand. She has more than 25 years' experience of working with the rural nursing workforce including the areas of research and education. Jean's work with rural nurses began in 1994 with the establishment of the National Centre for Rural Health in New Zealand, of which she was co-director. Jean has published two books and numerous journal publications.

Diana VanderWoude, RN, MS is the Sanford Health HR senior executive director of leadership, education and development, Sanford Health, Sioux Falls, South Dakota. Diana has 37 years' experience in healthcare and oversees learning strategies, career development and talent management across her institution. She has held leadership roles at state and national levels and serves on various boards and advisory councils. Previously, she was executive director for the SD Board of Nursing. Education and workforce development are core to her passion as a leader; Diana's work often involves strategic planning, collaborative partnerships, team-building and innovative program development. 
Audrey Snyder PhD, RN, ACNP is an associate professor and associate dean for Practice and Innovation in the School of Nursing at the University of Northern Carolina-Greensboro. Audrey's clinical and research interests include nursing education, rural underserved populations and evaluating methods to improve access to care in the US and globally, emergency medicine, disaster preparedness and response, engaging communities and international health and nursing history. She is a dynamic education and healthcare professional, with 35 years as a nurse and 20 as a nurse practitioner. She is certified as an Acute Care and Family Nurse Practitioner and gained a PhD in nursing from the University of Virginia in 2007. She is president of the International Rural Nurses Organization.

Elizabeth Merwin, PhD, RN, FAAN is dean and professor at the University of Texas at Arlington. Elizabeth is an accomplished nursing and health services researcher whose work has focused on improving care for underserved populations, particularly those in rural communities and minority populations. Her research programme has been consistently funded by $\mathrm{NIH}$ and other external funding agencies. Currently, she is conducting a study of the US Medicare population titled Reducing Health Disparities in SMI, Rural and Minority Populations. Previously, she was the director of a National Institutes of Health/National Institute of Nursing research programme where she was involved in many pilot studies including one on the incorporation of technology into care delivery. Earlier in her career, she was associate director and then director of a NIMH-funded rural mental health centre. She recently completed service as president of the Rural Nurse Organization.

Corey Hamilton Kilgore BS (Psychology), MS (Industrial/organisational Psychology) is executive director, Matson Halverson Christiansen Hamilton (MHCH) Foundation, Kimball, South Dakota. Corey is responsible for executing the mission of improving quality of life and creating opportunities for rural enterprise development. This work has mainly comprised programs that recognise the role of community development in rural health and those leveraging healthcare as a driver for rural economic development. Corey is an organisational development specialist with extensive experience in designing and applying organisational development and change management strategies and plans. Prior to joining $\mathrm{MHCH}$, she was a senior change management consultant with both Ernst \& Young and Hewlett Packard Corporation.

Lisa M. Feller, EdD, RN, CNE is academic director and associate professor, University of South Dakota Department of Nursing Pierre, South Dakota. Lisa has over 20 years of experience in nursing education, with expertise in adult health, rural health, leadership and quality improvement. She was a member of the Quality and Safety Education for Nurses (QSEN) pilot project and has provided consultation to nursing programs on the integration of QSEN competencies in curricula. In addition, Dr Feller has worked closely with community and practice partners to implement workforce development models in rural settings.

Correspondence to: Jean Ross, Otago Polytechnic, Dunedin, New Zealand. Email: jean.ross@op.ac.nz 


\section{REFERENCES}

Couper, I., Strasser, R., Rourke, J., \& Wynn-Jones, J. (20 I5). Rural health activism over two decades:The Wonca working party on rural practice 1992-2012. Rural and Remote Health, 15(3), 3245.

Ely, D. M., Driscoll A. K., \& Mathews T. J. (2017). Infant mortality rates in rural and urban areas in the United States, 2014 (NCHS data brief, No. 285). Hyattsville, MD: National Center for Health Statistics.

Gamm, L. D., Hutchison, L. L., Dabney, B. J., \& Dorsey, A. M., (2010) (Eds). Rural healthy people 20 1 0:A companion document to healthy people 2010 (Volume 2). College Station, TX:The Texas A \& M University System Health Science Center, School of Rural Public Health, Southwest Rural Health Research Center.

Garner, S. (20I4). Photo voice as a teaching and learning strategy for undergraduate nursing students. Nurse Education Today, 34, $1272-1274$

Hogarth, K., \& Rapata-Hanning, M. (2015). Māori health in Aotearoa New Zealand. In J. Craft and C. J. Gordon (Eds.), Understanding pathophysiology (pp. I 179-1 197). Sydney, Australia: Elsevier Australia.

Jones, C. A., Parker, T. S., Ahearn, M., Mishra, A.K., \& Veriyam, J. N. (2009). Health status and healthcare access for farm and rural populations. Washington, DC: US Department of Agriculture.

Ka'ai, T. M., \& Higgins, R. (2004). The Treaty of Waitangi. In T. M. Ka'ai, J. C. Moorfield, M. P. J. Reilly, \& S. Mosely (Eds.), Ki te whaiao: An introduction to Maori culture and society (pp. 151-162). Auckland, New Zealand: Pearson Education.

Leipert, B., \& Anderson, E. (2012). Rural nursing education: A photo voice perspective. Rural and Remote Health, I2, 206I.

Moy, E., Garcia, M. C., Bastian, B. Rossen, L. M., Ingram, D. D., Faul, M., Massetti, G. M., Thomas, C. C., Hong, Y., Yoon, P.W., \& Lademarco, M. F. (20 I7). Leading causes of death in nonmetropolitan and metropolitan areas - United States (MMWR Surveillance Summary 2017, 66 (NoSS- I). http://dx.doi.org/l0.15585/mmwr.ss660 Ial

Nagel, J., \& Jourdain, K. (2019). Worldview intelligence - Change the outcome. Resource training Booklet Developed for Sanford Health by Worldview Intelligence Inc, USA: Authors.

National Health Committee (20 I0). Rural health: Challenges of distance opportunities for innovation. Wellington: Author.

Orgera, K., \& Artiga, A. (2018, August). Disparities in health and health care: Five key questions and answers. Retrieved from https:// www.kff.org/disparities-policy/issue-brief/disparities-in-health-and-health-care-five-key-questions-and-answers/

Ross J. (2016). 'Place' matters to rural nurses [Unpublished PhD thesis]. University of Otago.

Ross, J., \& Crawley, J. (20।8). (Eds.), Stories of nursing in rural Aotearoa: A landscape of care. Dunedin, New Zealand: Rural Health Opportunities.

Ross, J., Crawley, J., \& Mahoney, L. (2017). Sustainable community development: Student nurses making a difference. Scope: Contemporary Research Topics: Learning \& Teaching, 4, 8-17.

United Nations (2019). Sustainable development goals. Retrieved from https://www.un.org/sustainabledevelopment/sustainabledevelopment-goals/

World Health Organization (2013). World health statistics 2013. Geneva, Switzerland: Author 